\title{
Association between anxiety symptoms and problematic alcohol use in adolescents
}

\author{
Associação entre sintomas ansiosos \\ e uso problemático de álcool em adolescentes
}

\author{
Marianna de Abreu Costa, ${ }^{1}$ Giovanni Abrahão Salum Junior, ${ }^{2}$ Luciano Rassier Isolan, ${ }^{3}$ Jandira Rahmeier Acosta, ${ }^{1}$ \\ Rafaela Behs Jarros, ${ }^{2}$ Carolina Blaya, ${ }^{4}$ Lísia Von Diemen, ${ }^{5}$ Gisele Gus Manfro ${ }^{6}$
}

\begin{abstract}
Background: Anxiety disorders are highly prevalent, affecting approximately $10 \%$ of individuals throughout life; its onset can be detected since early childhood or adolescence. Studies in adults have shown that anxiety disorders are associated with alcohol abuse, but few studies have investigated the association between anxiety symptoms and problematic alcohol use in early ages.

Objective: To evaluate if anxiety symptoms are associated with problematic alcohol use in young subjects.

Methods: A total of 239 individuals aged $10-17$ years were randomly selected from schools located in the catchment area of Hospital de Clínicas de Porto Alegre. The Screen for Child Anxiety-Related Emotional Disorders (SCARED) was used to evaluate the presence of anxiety symptoms, and the Alcohol, Smoking and Substance Involvement Screening Test (ASSIST), to evaluate alcohol use.

Results: One hundred twenty-seven individuals (53.1\%) reported having already used alcohol. Of these, 14 individuals showed problematic alcohol use $(5.8 \%)$. There was no association between lifetime use of alcohol and anxiety symptoms, but mean SCARED scores in individuals with problematic alcohol use was higher if compared to those without problematic use, even after adjustment for age and gender $(29.9 \pm 8.5$ vs. $23.7 \pm 11.8, p<0.001)$. Conclusions: Despite the limitation of a cross-sectional design, our study suggests that anxiety symptoms are associated with problematic alcohol use early in life.
\end{abstract}

Keywords: Child, adolescent, anxiety, alcohol drinking.

\section{Resumo}

Introdução: Os transtornos de ansiedade possuem alta prevalência, afetando aproximadamente $10 \%$ dos indivíduos ao longo da vida; seu início pode ser detectado já na infância e na adolescência. Estudos em adultos demonstram que a ansiedade está associada ao abuso de álcool. No entanto, poucos estudos investigaram a associação entre sintomas ansiosos e o uso problemático de álcool em indivíduos jovens.

Objetivo: Avaliar se os sintomas de ansiedade estão relacionados com uso problemático de álcool em jovens.

Métodos: Um total de 239 indivíduos com idade de 10-17 anos foram aleatoriamente selecionados em escolas pertencentes à área de abrangência do Hospital de Clinicas de Porto Alegre. A escala Screen for Child Anxiety-Related Emotional Disorders (SCARED) foi utilizada para avaliar a presença de sintomas ansiosos, e a escala Alcohol, Smoking and Substance Involvement Screening Test (ASSIST), para avaliar o uso de álcool.

Resultados: Cento e vinte e sete indivíduos $(53,1 \%)$ já haviam utilizado bebida alcoólica. Desses, 14 indivíduos mostraram uso problemático de álcool (5,8\%). Não foi observada associação entre ter usado álcool na vida e sintomas ansiosos. Porém, o escore médio da SCARED em indivíduos com uso problemático de álcool foi maior quando comparado com o escore daqueles sem uso de álcool problemático, mesmo após ajuste para idade e gênero $(29,9 \pm 8,5$ vs. $23,7 \pm 11,8, p<0,001)$.

Conclusões: Apesar das limitações impostas pelo desenho transversal, nosso estudo sugere que sintomas de ansiedade estão associados com o uso problemático de álcool em indivíduos jovens. Descritores: Criança, adolescente, ansiedade, etanol.

\footnotetext{
${ }^{1}$ Anxiety Disorders Program for Child and Adolescent Psychiatry (PROTAIA), Hospital de Clínicas de Porto Alegre (HCPA), Universidade Federal do Rio Grande do Sul (UFRGS), Porto Alegre, RS, Brazil. ${ }^{2}$ PROTAIA, HCPA, UFRGS, Porto Alegre, RS, Brazil. National Institute of Developmental Psychiatry for Children and Adolescents (INPD), Conselho Nacional de Desenvolvimento Científico e Tecnológico (CNPq). Graduate Program in Medical Sciences: Psychiatry, HCPA, UFRGS, Porto Alegre, RS, Brazil. ${ }^{3}$ PROTAIA and Graduate Program in Medical Sciences: Psychiatry, HCPA, UFRGS, Porto Alegre, RS, Brazil. ${ }^{4}$ PROTAIA, HCPA, UFRGS, Porto Alegre, RS, Brazil. Department of Clinical Medicine: Psychiatry, Universidade Federal de Ciências Médicas de Porto Alegre (UFCSPA), Porto Alegre, RS, Brazil. ${ }^{5}$ Center for Drug and Alcohol Research, HCPA, UFRGS, Porto Alegre, RS, Brazil. ${ }^{6}$ PROTAIA, HCPA, UFRGS, Porto Alegre, RS, Brazil. INPD, CNPq. Graduate Program in Medical Sciences: Psychiatry, HCPA, UFRGS, Porto Alegre, RS, Brazil. Graduate Program in Neuroscience, Health Basic Sciences Institute (ICBS), UFRGS, Porto Alegre, RS, Brazil.

Financial support: Fundo de Incentivo à Pesquisa - Hospital de Clínicas de Porto Alegre (FIPE-HCPA), Conselho Nacional de Desenvolvimento Científico e Tecnológico (CNPq), and Fundação de Amparo à Pesquisa do Estado do Rio Grande do Sul (FAPERGS).

Submitted Jun 21 2012, accepted for publication Aug 16 2012. No conflicts of interest declared concerning the publication of this article.

Suggested citation: Costa MA, Salum GA, Isolan LR, Acosta JR, Jarros RB, Blaya C, et al. Association between anxiety symptoms and problematic alcohol use in adolescents. Trends Psychiatry Psychother. 2013;35(2):106-10.
} 


\section{Introduction}

Anxiety disorders are among the most prevalent psychiatric conditions, affecting approximately $28.8 \%$ of individuals throughout life. ${ }^{1}$ Moreover, these disorders are characterized by having an early onset, affecting almost $5.2 \%$ of subjects aged 7 to 14 years according to a Brazilian epidemiological study. ${ }^{2}$ Studies evaluating adult samples have demonstrated that anxiety disorders are associated with problematic alcohol use, ${ }^{3}$ but few studies have investigated this association early in life.

Alcohol is the drug most widely used in the general population and also among adolescents. Laranjeira et al. reported a prevalence of $28 \%$ of heavy alcohol use, $3 \%$ of alcohol abuse, and $9 \%$ of dependence in a Brazilian adult sample. ${ }^{4}$ Lifetime prevalence of alcohol use among Brazilian adolescents has been informed to range from $34^{5}$ to $62 \%,{ }^{6}$ reaching higher rates in females. While $6.7 \%$ of the population is comprised of heavy users, the rate of frequent use reaches $11.7 \% .^{7}$ Furthermore, alcohol consumption has accounted for 80,000 deaths per year from 2001 to 2005 in the U.S., and is considered one of the most common preventable causes of death. ${ }^{8}$

Comorbidity between anxiety disorders and alcohol use in adults is well described in the literature. Degenhardt et al. showed that the association between alcohol use and anxiety in adults shows a J-shaped curve, with light users having the lowest rates of anxiety disorders, and those with dependence showing the highest rates of anxiety. ${ }^{9}$ Moreover, the frequency of alcohol use as a self-medication in anxious individuals differs depending on the type of anxiety disorder. For example, studies have shown a prevalence of $3.3 \%$ in individuals with specific phobia, ${ }^{10} 7.9 \%$ in those with social anxiety disorder/public speaking subtype, ${ }^{11}$ and $18.3^{10}$ to $35.6 \%{ }^{11}$ in patients diagnosed with generalized anxiety disorder. In a representative sample of 43,093 U.S. adults, Schneier et al. found a positive association between social anxiety disorder and alcohol dependence $(\mathrm{OR}=2.8)$ and alcohol abuse $(\mathrm{OR}=1.2) .{ }^{12}$ Fewer studies have investigated this association in adolescents. Saban et al. described a prevalence of $43 \%$ of anxiety disorder in 43 adolescents hospitalized for alcohol dependence or use. ${ }^{13}$ Data from community studies investigating earlier patterns of this comorbidity are lacking.

The aim of this study was to investigate whether anxiety symptoms were associated with problematic alcohol use in a community sample of adolescents. Our hypothesis was that adolescents with anxiety symptoms would show higher rates of alcohol use and would use it more frequently when compared with those without anxiety symptoms. Also, we hypothesize that anxiety symptoms are associated with problematic alcohol use in adolescence, as already demonstrated in adult samples.

\section{Materials and methods}

Students aged 10 to 17 years and attending schools located in the catchment area of the primary care unit of Hospital de Clínicas de Porto Alegre, in the city of Porto Alegre, southern Brazil, were enrolled in the study from April 2008 to September 2009, resulting in a total sample of 2,537 individuals. Detailed information about the study design and sample is described elsewhere. ${ }^{14}$ Before the study, both students and their parents received written information about the study; parents who did not want their children to participate were required to sign an informed dissent form. In addition, written informed consent was obtained from all participating schools. The study design was reviewed and approved by the Ethics Committee of Hospital de Clínicas de Porto Alegre (protocol no. 08-017).

Of the initial sample, 239 individuals were randomly selected to answer the Screen for Child Anxiety-Related Emotional Disorders (SCARED), for the assessment of anxiety symptoms, and the Alcohol, Smoking and Substance Involvement Screening Test, modified for self-application (ASSIST), to evaluate alcohol use.

The SCARED is a screening scale widely used to assess anxiety symptoms in children and adolescents. ${ }^{15,16}$ It consists of five subscales (somatic/panic, generalized anxiety, separation anxiety, social phobia, and school phobia) and a total of 41 questions that have to be answered with regard to symptom frequency using a 3-point scale, as follows: 0 (almost never), 1 (sometimes), and 2 (often). The SCARED total score, derived by summing the responses of the 41 items, may range from 0 to 82 . The SCARED has been validated for use in Brazilian children and adolescents and has shown good psychometric properties. ${ }^{17}$

The ASSIST was developed by the World Health Organization and is used to screen for different levels of problems with substances in general. It has been validated in Portuguese language and comprises seven questions related to the frequency and lifetime use of substances, problems and concerns of others regarding substance use, impairment in tasks, and unsuccessful attempts to stop or reduce substance use (either nicotine, alcohol, marijuana, cocaine, inhalants, or other substances). ${ }^{18}$ The ASSIST final score may suggest abuse and/or dependence for each drug assessed. Each question has different options of answers, with different ratings. ${ }^{18}$

The sample was dichotomized according to problematic alcohol use assessed by questions 2 to 7 of the ASSIST scale, where individuals scoring 0 to 10 were considered as no problematic alcohol use, and those scoring 11 or above were considered to present problematic use. Individuals 
scoring from 11 to 26 were grouped together with those scoring higher than 27 , as only three individuals showed scores $\geq 27$ (insufficient statistical power for an individual analysis of this more severe group). Lifetime alcohol use and frequency of use were also calculated according to the ASSIST scale. As a result, individuals answering never and 1 or 2 times (in lifetime) were considered as presenting a low frequency of alcohol use, and those answering weekly and every day or almost every day were considered as high frequency. The response monthly was considered as low frequency in males and as high frequency in females, taking into consideration the different amounts of alcohol used to determine substance use and risk patterns between genders. ${ }^{19}$

\section{Statistical analysis}

Normal distribution and equality of variance were assessed prior to any statistical analysis using the Kolmogorov-Smirnov test and Levene's test. Data are presented as count (\%), mean (M), and standard deviation (SD). Prevalence ratio (RP) and 95\% confidence interval $(95 \% \mathrm{CI})$ were calculated. ASSIST results were dichotomized, and the chi-square test was used to assess the association between gender and problematic alcohol use. The Student $t$ test was used to assess associations between age and problematic alcohol use and also between SCARED results and gender.

The association of problematic alcohol use with gender, age, and SCARED scores was assessed using Poisson regression. Variables showing an association with problematic alcohol use or SCARED scores equivalent to $p<0.2$ were included in the analysis. Poisson regression was also used to assess associations between different anxiety symptoms and problematic alcohol use in a multivariate model.

All analyses were performed using the Statistical Package for the Social Sciences (SPSS) version 17.0. Significance was set at $p<0.05$.

\section{Results}

A total of 239 individuals were evaluated, and 131 $(54.8 \%)$ were females. Mean age in the whole sample was $14.2 \pm 2.40$ years. A total of 127 individuals (53.1\%) reported lifetime use of alcohol. Of these, 14 individuals showed problematic alcohol use, accounting for $5.9 \%$ of the sample.

Lifetime use of alcohol was not significantly associated with SCARED scores $(p=0.681)$. However, individuals whose alcohol use was rated as highly frequent showed higher scores on the SCARED scale when compared to those with a lower frequency of alcohol use, even after adjustment for age and gender ( $M=28.1$ vs. 22.9, $p=0.02$ ).

In the bivariate analysis, individuals with problematic alcohol use differed from those with no problematic use in being older $(16.4 \pm 2.2$ vs. $14 \pm 2.3$ years, $p<0.001)$ and more frequently male (71.4 vs. $43.11 \%, p=0.043)$. Mean SCARED score in the total sample was $24.1 \pm 11.76$, and it was higher among individuals with problematic alcohol use as compared to those without problematic use, but the difference was marginal considering the probability value $(29.92 \pm 8.5$ vs. $23.75 \pm 11.8, p=0.057)$. After controlling for confounders (gender and age), anxiety symptoms were significantly associated with problematic alcohol use ( $P R=1.054,95 \%$ CI 1.02-1.08, $p<0.001)$.

The anxiety symptoms most often associated with alcohol problems in separated multivariate models adjusted for age and gender were: generalized anxiety symptoms $(P R=1.22,95 \% C I 1.13-2.1, p<0.001)$, separation anxiety symptoms ( $P R=1.21,95 \% C I 1.11$ $1.31, \mathrm{p}<0.001)$, and panic symptoms $(\mathrm{PR}=1.11$, $95 \% C I 1.01-1.23, p=0.03)$. School phobia symptoms $(P R=1.04,95 \% C I 10.65-1.66, p=0.86)$ and social anxiety symptoms $(\mathrm{PR}=1.08,95 \% \mathrm{CI} 0.96-1.2, \mathrm{p}=$ 0.18 ) were not associated with problematic alcohol use in our sample.

\section{Discussion}

The prevalence of alcohol use in our sample was $53.1 \%$, which is in agreement with other studies that have reported prevalence rates ranging from $34^{5}$ to $62 \%{ }^{6}$ among adolescents. We found a higher prevalence of alcohol use in male and older adolescents, as also previously reported. ${ }^{5}$ Moreover, corroborating our initial hypothesis, we found a higher prevalence of anxiety symptoms in individuals with problematic alcohol use after adjustment for confounders.

The literature describes different patterns of alcohol use according to different types of anxiety disorders. ${ }^{10,11,20,21}$ Our data showed a higher prevalence of problematic alcohol use in the presence of symptoms of panic disorder and generalized anxiety disorder, which is in agreement with previous studies. ${ }^{10,11,20-22}$ However, we did not find an association between social phobia symptoms and problematic alcohol use, as reported in some studies assessing adults ${ }^{10}$ and adolescents. ${ }^{22}$ These controversial findings could be due to methodological differences in the assessment of anxiety. For instance, while previous studies have reported associations between alcohol use and different diagnoses of anxiety disorders, we evaluated anxiety symptoms using a screening scale. As a result, our study did not confirm 
the association between a diagnosis of anxiety disorder and alcohol use, but rather the association between anxiety symptoms and problematic alcohol use. Other possible explanation for these differences between the findings could be a beta error in our study, as only five individuals showed social anxiety symptoms.

Recognizing the association between anxiety symptoms and problematic alcohol use in a population of youth may prevent alcohol-related morbidity and mortality through strategies focused on individuals with anxiety symptoms and thus the early recognition of individuals at a greater risk for developing alcohol problems. Higher levels of alcohol use have been reported for $52 \%$ of deaths among Brazilians aged 15 to 54 years. ${ }^{23}$ In addition, in 2000, $40 \%$ of the fatalities in traffic accidents in the U.S. were related to alcohol use. ${ }^{9}$ Students who commit suicide are more often under the acute effect of alcohol, ${ }^{24}$ and the use of this substance has been shown to quadruplicate the chance of violence among men. ${ }^{24}$ The risk of death by drowning, falls, and suicide is higher in alcoholic subjects. ${ }^{9}$ At an early age, alcohol consumption increases the chance of using tobacco and other drugs, and also of worsening its own pattern of use. ${ }^{6}$ Finally, alcohol is also a risk factor for different medical conditions. ${ }^{23,25}$

The literature has demonstrated that non-recognition and non-treatment of anxiety disorders may pose difficulties to and even cause the failure of alcoholism treatment. ${ }^{12}$ Some studies have shown that anxiety can contribute to the maintenance and relapse of alcohol abuse and dependence disorders. ${ }^{3,26}$ In addition, anxiety may worsen alcohol abuse and dependence. ${ }^{12}$ Anxious individuals who use alcohol as a self-medication have an increased chance of developing other comorbidities, e.g., mood disorder, ${ }^{11,12}$ substance use disorder, ${ }^{11}$ suicidal ideation and suicide attempt, ${ }^{11}$ and personality disorder. ${ }^{10}$ Moreover, they tend to have a poorer quality of life $\mathrm{e}^{27}$ and increased rates of health care system use. ${ }^{27}$

The direction of the association between anxiety and problematic alcohol use is controversial in the recent literature: while some studies suggest that alcohol precedes anxiety, ${ }^{3}$ others indicate that anxiety disorder precedes problems with alcohol. ${ }^{3,21}$ Alcohol can be used as a selfmedication in anxious individuals with social interaction difficulties (pro-exposure factor). Falk et al. showed that social anxiety disorder and specific phobia usually precede problematic alcohol use. ${ }^{21}$ In a sample with adults, social anxiety disorder preceded alcohol dependence in $79.7 \%$ of comorbid cases. ${ }^{12}$ Conversely, anxiety may result from problematic alcohol use or even from the withdrawal syndrome. Alcohol abuse or dependence tends to occur prior to generalized anxiety disorder and panic disorder. ${ }^{22}$
Because our study has a cross-sectional design, our results do not allow to suggest a causal relationship between problematic alcohol use and anxiety symptoms. The lack of association between lifetime alcohol use and anxiety symptoms in our study may possibly be explained by a beta error due to our small sample size, as well as because we analyzed different types of anxiety. Moreover, we could not evaluate other confounding comorbidities, such as depression, because this information was not available. Another limitation is the use of self-report instruments, even though most studies have suggested that self-report instruments provide valid information on the use of alcohol by adolescents. ${ }^{28}$ Finally, an additional limitation refers to the fact that analysis was based on symptoms rather than on diagnosis. It is interesting to note that, even in the absence of a full-blown disorder, the presence of anxiety symptoms allowed to identify individuals already at risk for developing alcohol-related disorders. This finding becomes even more important if we consider that alcoholism is a more difficult disease to treat when compared to anxiety disorders. ${ }^{29}$

We did not find an association between lifetime alcohol use (experimentation) and anxiety symptoms, but the latter was associated with problematic and highly frequent alcohol use. Adolescence is an important stage, marked by impulsivity, family conflicts, and transgression. Those characteristics reflect the omnipotence and curiosity typically observed in youths and may lead one to engage in risk behaviors by searching for new sensations and pleasures. ${ }^{30}$ In addition, alcohol products are widely offered ${ }^{31}$ and used, ${ }^{32}$ easily accessible, ${ }^{31}$ although forbidden for adolescents in Brazil. Thus, the higher rate of alcohol experimentation observed in our sample is consistent with characteristics inherent to adolescence and maybe to the Brazilian setting, regardless of the presence of anxiety symptoms. From a different standpoint, however, our findings do suggest that frequent and problematic use of alcohol may represent a condition potentially associated with pathological traits such as anxiety symptoms.

In sum, this study corroborates data previously described for adults and shows that the association between anxiety and alcohol problems can be detected within a dimensional perspective, i.e., in the presence of anxiety symptoms, not necessarily disorders. This finding can contribute to the design and implementation of preventive efforts among individuals at risk. Longitudinal studies that identify the presence of anxiety disorders in children and, subsequently, evaluate the development of alcohol-related disorders, are needed to confirm our findings. 


\section{Acknowledgments}

We thank Cristiano Tschiedel Belem da Silva, MD, for reviewing this manuscript, and Marilyn Agranonik, MSc, for the statistical analyses.

\section{References}

1. Kessler RC, Berglund $P$, Demler $O$, Jin $R$, Merikangas KR, Walters EE. Lifetime prevalence and age-of-onset distributions of DSM-IV disorders in the National Comorbidity Survey Replication. Arch Gen Psychiatry. 2005;62:593-602.

2. Fleitlich-Bilyk B, Goodman R. Prevalence of child and adolescent psychiatric disorders in southeast Brazil. J Am Acad Child Adolesc Psychiatry. 2004;43:727-34.

3. Kushner MG, Abrams K, Borchardt C. The relationship between anxiety disorders and alcohol use disorders: a review of major perspectives and findings. Clin Psychol Rev. 2000;20:149-71.

4. Laranjeira R, Pinsky I, Sanches M, Zaleski M, Caetano R. Alcohol use patterns among Brazilian adults. Rev Bras Psiquiatr. 2010;32:231-41.

5. Pinsky I, Sanches M, Zaleski M, Laranjeira R, Caetano R. Patterns of alcohol use among Brazilian adolescents. Rev Bras Psiquiatr. 2010;32:242-9.

6. Vieira DL, Ribeiro M, Laranjeira R. Evidence of association between early alcohol use and risk of later problems. Rev Bras Psiquiatr. 2007;29:222-7

7. Galduróz JC, Noto AR, Fonseca AM, Carlini EA. V levantamento nacional sobre o consumo de drogas psicotrópicas entre estudantes do ensino fundamental e médio da rede pública de ensino nas 27 capitais brasileiras, 2004. 2006. Álcool e Drogas sem Distorção [web site]. http://apps.einstein.br/ alcooledrogas/novosite/atualizacoes/ac_133.htm. Accessed 2010 Jun 6.

8. Centers for Disease Control and Prevention (CDC). Alcoholattributable deaths and years of potential life lost: United States, 2001. MMWR Morb Mortal Wkly Rep. 2004;53:866-70.

9. Degenhardt L, Hall W, Lynskey M. Alcohol, cannabis and tobacco use among Australians: a comparison of their associations with other drug use and use disorders, affective and anxiety disorders, and psychosis. Addiction. 2001; $96: 1603-14$.

10. Robinson J, Sareen J, Cox BJ, Bolton J. Self-medication of anxiety disorders with alcohol and drugs: results from a nationally representative sample. J Anxiety Disord. 2009;23:38-45.

11. Bolton J, Cox B, Clara I, Sareen J. Use of alcohol and drugs to self-medicate anxiety disorders in a nationally representative sample. J Nerv Ment Dis. 2006;194:818-25.

12. Schneier FR, Foose TE, Hasin DS, Heimberg RG, Liu SM, Grant $\mathrm{BF}$, et al. Social anxiety disorder and alcohol use disorder comorbidity in the National Epidemiologic Survey on Alcohol and Related Conditions. Psychol Med. 2010;40:977-88.

13. Saban A, Flisher AJ. The association between psychopathology and substance use in young people: a review of the literature. J Psychoactive Drugs. 2010;42:37-47.

14. Salum GA, Isolan LR, Bosa VL, Tocchetto AG, Teche SP, Schuch I, et al. The multidimensional evaluation and treatment of anxiety in children and adolescents: rationale, design, methods and preliminary findings. Rev Bras Psiquiatr. 2011;33:181-95.

15. Birmaher B, Brent DA, Chiappetta L, Bridge J, Monga S, Baugher M. Psychometric properties of the Screen for Child Anxiety Related Emotional Disorders (SCARED): a replication study. J Am Acad Child Adolesc Psychiatry. 1999;38:1230-6.
16. Birmaher B, Khetarpal S, Brend, Cully M, Balach L, Kaufman J, et al. The Screen for Child Anxiety Related Emotional Disorders (SCARED): scale construction and psychometric characteristics. J Am Acad Child Adolesc Psychiatry. 1997;36:545-53.

17. Isolan L, Salum GA, Osowski AT, Amaro E, Manfro GG. Psychometric properties of the Screen for Child Anxiety Related Emotional Disorders (SCARED) in Brazilian children and adolescents. J Anxiety Disord. 2011;25:741-8.

18. Henrique IF, De Micheli D, Lacerda RB, Lacerda LA, Formigoni ML. Validation of the Brazilian version of Alcohol, Smoking and Substance Involvement Screening Test (ASSIST). Rev Assoc Med Bras. 2004;50:199-206.

19. De Fiellen DA, Reid C, O'Connor PG. Outpatient management of patients with alcohol problems. Ann Inter Med. 2000; $133: 815-27$

20. Arch J], Craske MG, Stein MB, Sherbourne CD, Roy-Byrne PP. Correlates of alcohol use among anxious and depressed primary care patients. Gen Hosp Psychiatry. 2006;28:37-42.

21. Zimmermann $P$, Wittchen HU, Höfler $M$, Pfister $H$, Kessler RC, Lieb R. Primary anxiety disorders and the development of subsequent alcohol use disorders: a 4-year community study of adolescents and young adults. Psychol Med. 2003;33:1211-22.

22. Falk DE, Yi HY, Hilton ME. Age of onset and temporal sequencing of lifetime DSM-IV alcohol use disorders relative to comorbid mood and anxiety disorders. Drug Alcohol Depend. 2008;94:234-45.

23. Zaridze D, Brennan $P$, Boreham J, Boroda A, Karpov R, Lazarev A, et al. Alcohol and cause-specific mortality in Russia: a retrospective case-control study of 48,557 adult deaths. Lancet. 2009;373:2201-14.

24. Zaleski M, Pinsky I, Laranjeira R, Ramisetty-Mikler S, Caetano $R$. Intimate partner violence and alcohol consumption. Rev Saude Publica. 2010;44:53-9.

25. Thun MJ, Peto R, Lopez AD, Monaco JH, Henley SJ, Heath Jr $\mathrm{CW}$, et al. Alcohol consumption and mortality among middleaged and elderly U.S. adults. N Engl J Med. 1997;337:1705-14.

26. Kushner MG, Abrams K, Thuras $P$, Hanson KL, Brekke $M$, Sletten S. Follow-up study of anxiety disorder and alcohol dependence in comorbid alcoholism treatment patients. Alcohol Clin Exp Res. 2005;29:1432-43.

27. Robinson JA, Sareen J, Cox BJ, Bolton JM. Correlates of selfmedication for anxiety disorders: results from the National Epidemiologic Survey on Alcohol and Related Conditions. J Nerv Ment Dis. 2009;197:873-8.

28. Needle R, McCubbin H, Lorence J, Hochhauser M. Reliability and validity of adolescent self-reported drug use in a family-based study: a methodological report. Int J Addict. 1983; 18:901-12

29. Wesner RB. Alcohol use and abuse secondary do anxiety. Psychiatr Clin North Am. 1990;13:699-713.

30. Miller JW, Naimi TS, Brewer RD, Jones SE. Binge drinking and associated health risk behaviors among high school students. Pediatrics. 2007;119:76-85.

31. Laranjeira RR. Brazil's market is unregulated. BMJ. 2007;335:735.

32. Galduróz JC, Carlini EA. Use of alcohol among the inhabitants of the 107 largest cities in Brazil - 2001. Braz J Med Biol Res. 2007;40:367-75.

\section{Correspondence}

Gisele Gus Manfro

Anxiety Disorders Program for Child and Adolescent

Psychiatry (PROTAIA)

Hospital de Clínicas de Porto Alegre (HCPA)

Rua Ramiro Barcelos, 2350

90035-903 - Porto Alegre, RS - Brazil

Tel./Fax: +55 (51) 3359.89.83

E-mail: gmanfro@gmail.com 